\title{
Risk Analysis of Urban Waterlogging Disaster based on Large Data Simulation

\author{
Bingde Deng ${ }^{1, a}$ and Wen $\mathrm{Li}^{1, \mathrm{~b}}$ \\ ${ }^{1}$ Jilin University of Finance and Economics, Changchun, Jilin, 130117 \\ a dengbingde@yeah.net, b liwen@126.com
}

Keywords: Large Data, Simulation, Urban Flooding, Risk

\begin{abstract}
This paper uses the principle and method of simplifying the urban waterlogging model to set up a model of waterlogging problem in a horizontal bridge of Changchun. This model is combined with the precipitation data from 1950 to 2010 in Changchun City, and the probability of waterlogging risk at the bottom of the bridge is calculated by simulation method. The results show that the drainage network is not suitable for the heavy rainfall, and the greening rate on both sides of the road can reduce the risk of waterlogging caused by moderate intensity rainfall. The innovation of this paper is to combine simulation with large rainfall data, which is of practical significance to predict the risk of urban waterlogging.
\end{abstract}

\section{Introduction}

City waterlogging is due to heavy precipitation or continuous precipitation over urban drainage capacity caused by the phenomenon of urban waterlogging disasters. The "7.21" heavy rain disaster in Beijing shows that the meteorological department can give the forecast of rainfall in advance, but it is estimated that the risk of the rainstorm is not enough, and the water accumulation in the city is deep, resulting in the loss of personnel and property. 2010 Ministry of Housing and Urban and Rural Construction conducted a survey of 351 cities and found that in 2008-2010, 62\% of urban waterlogging incidents occurred. In September 2013, the State Council issued the Opinions on Strengthening the Construction of Urban Infrastructure. The opinion points out that it takes about 10 years to build a better urban drainage and flood control system.

Although the rainfall in the northeastern region is lower than that in the south, the "7.21 heavy rain disaster" in Beijing also sounded the alarm to the urban construction in the northeast. With the sinking of the overpass, the subway, the tunnel in the north gradually increased, the relevant disaster-prone areas of risk assessment is an urgent task, should not be considered that the northern city there is no possible urban waterlogging occurred. Therefore, it is an important task to analyze and quantify the risk of occurrence of waterlogging in a specific area of the city by improving the knowledge of the city's waterlogging model and using the knowledge and relevant data of each subject. This will help the relevant decision-making departments to make corresponding assessment and Plan.

\section{Urban waterlogging problem}

Urban waterlogging problems related to meteorology, geographic information systems, civil engineering, water supply and drainage and other disciplines and professional, is a complex system engineering. In recent years, the US Environmental Protection Agency (EPA) funded the study of urban rainwater management model (SWMM). The model mainly includes runoff, transportation and storage (processing) and other modules, is the application of a more extensive model. Similar to the 1977 US Army Corps of Engineers (STORM) and the 1978 Wallingford model (Wallingford proceed) and other application models. These models have established the corresponding mathematical model for the problems of precipitation process, ground runoff, pipe network drainage, rain and sewage confluence, and the computer has simulated the waterlogging condition under the 
corresponding conditions.

ZHANG Dong-dong (2014) Based on the theory of natural disaster risk assessment, the mechanism of urban waterlogging formation and risk assessment are summarized. From the planning, construction and management of three levels of urban waterlogging response to the overall thinking and technical framework, and pointed out the corresponding key technical issues. (SUWM), this model chooses the simulation of the central urban area of Shanghai. The results show that the waterlogging risk caused by different precipitation intensity and ground elevation is quite different. Qin Yun han (2016) used the mathematical model to simulate the surface runoff process, and analyzed the interrelationship between urban waterlogging and runoff pollutants.

In summary, the mathematical model of "urban waterlogging model" has been basically mature, the model contains the analysis of rainfall, infiltration, runoff, drainage process of the mathematical model. For the different types of waterlogged areas such as concave overpass, culverts, subway stations, underground parking lots are scattered research, the relevant mathematical model is also close to the basic. But the risk assessment of waterlogging problem is relatively weak.

\section{Urban Waterlogging Risk Assessment.}

The urban waterlogging risk assessment is a comprehensive risk factor and its data to give a specific probability of the risk of waterlogging in a particular area of the city, and to assess the loss. There are three types of current risk assessment:

Historical disaster mathematical statistics. This method uses the method of mathematical statistics to analyze the data of historical disasters, find out the law of disaster development, establish the statistical model of disaster occurrence probability and its influencing factors, and estimate the possible losses caused by future disasters. Benito built a methodology for assessing urban floods based on historical data from the past 1000 years and 50 years of normative records. The comprehensive index method. The method is based on the characteristics of waterlogging to select a certain index system, and then through a series of mathematical methods to determine the weight of the indicators, the regional flood risk assessment value. Rhododendron and so on from the disaster environment attributes, bearing the social environment and the characteristics of disaster factors, to build a comprehensive assessment of flood risk assessment index system, and the results applied to the Xiangjiang River Basin risk assessment. Hydrological mechanics model and simulation method. In this method, the flooding of urban floods, flooding depth and flooding can be caused by rainstorms in different scenarios by setting up different frequency rainstorm scenarios, using the production and flow model and flood evolution model to simulate them. Foreign commercial software Wallingford and Mike-SWMM provide some general features.

\section{Urban Waterlogging Model}

Choosing the appropriate hydrological model is the key to the simulation of waterlogging. The "city waterlogging model" usually contains the following four models.

(1) Ground elevation model. The main function of the DEM model is to find the location of the waterlogging point. With the support of the GIS system, the collected ground elevation information is processed to complete the identification of the waterlogging point.

(2) Precipitation model. The precipitation model describes the quantitative relationship between the rainfall and the rainfall recurrence period and the rainfall time. The precipitation model is basically completed by the rainstorm intensity formula. The formula is as follows:

$$
i=\frac{A_{1}\left(1+c \lg ^{T_{e}}\right)}{(t+b)^{n}}
$$

$\mathrm{i}$ is the design rainfall intensity ( $\mathrm{mm} / \mathrm{min}$ ), is designed to reproduce the rainfall (a), for the rainstorm with a designated rainfall of 1 year, $t$ is the rainfall duration (min), b, C and $n$ are specific parameter.

(3) Production and convergence model. The model of runoff generation describes the process of rainwater falling to the ground by vegetation, trapping, evaporation, low-lying retention, and 
infiltration factors. Usually expressed by the formula:

$$
R(t)=\int_{0}^{t} i d t-\int_{0}^{t} i_{n} d t-\int_{0}^{t} e d t-\int_{0}^{t} s_{d} d t-\int_{0}^{t} f d t
$$

Where $\mathrm{R}(\mathrm{t})$ is the surface runoff at time $\mathrm{t}, \mathrm{i}$ is the rainfall intensity, is the vegetation interception, $\mathrm{e}$ is the evaporation rate, is the filling depression rate, $\mathrm{f}$ is the infiltration rate. Vegetation interception and evaporation are usually negligible in these factors, and the greatest factor affecting ground runoff is the rate of infiltration.

(4) Drainage model. The drainage model mainly describes the actual drainage capacity of the drainage pipe network under the road or building floor. The size of the drainage capacity is mainly affected by the number and diameter of the drain. Drainage capacity of the Manning formula is described as follows:

$$
V_{d}=\frac{1}{n} W R^{2 / 3} S^{1 / 2}
$$

Where $\mathrm{n}$ is the wall roughness, $\mathrm{w}, \mathrm{R}, \mathrm{S}$ are the cross-sectional area, the hydraulic radius and the bottom slope.

\section{Calculation Method of Waterlogging Risk based on Large Data}

In summary, the historical disaster statistics and comprehensive index method there are too many indicators, the probability of disaster probability error is too large. Hydrological mechanics model and simulation method are the development trend of waterlogging assessment. However, the analysis of waterlogging risk in the relevant software belongs to the sensitivity analysis, and the corresponding scenario setting belongs to the numerical simulation. The precipitation data involved in the calculation does not reflect the historical distribution of the rainfall data, and the value of the rainfall data is not fully excavated.

Figure 1 is the nuclear density estimate for 4300 precipitation (daily rainfall) in Changchun during 1950 to 2010. It can be seen from the figure that most of the daily rainfall is less than 200 $(0.1 \mathrm{~mm}), 200-400$ range, 400-600 range is rapidly reduced, the daily rainfall of more than 600 belongs to the "reproduction period" larger rainfall $(t=50,100,500 \ldots)$, but also because of these extreme rainfall makes the city waterlogging occurred.

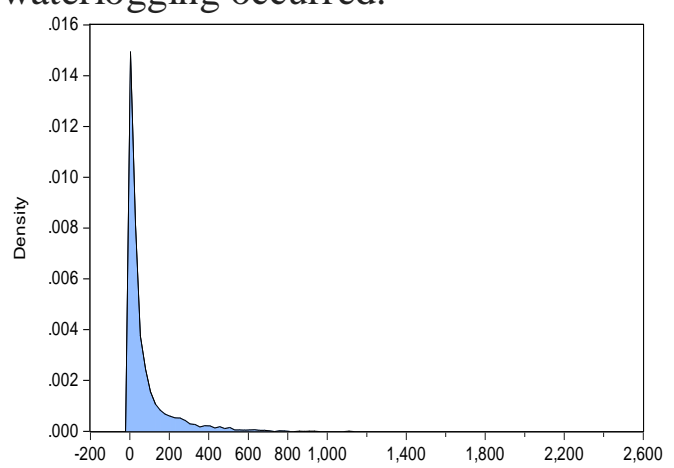

Figure 1 Changchun City 1950 - 2010 rainfall distribution $(0.1 \mathrm{~mm})$

Mining the historical rainfall data value is the application of statistical simulation in the "self-help" (bootstrap), its sampling constitutes a "waterlogging risk data set." And then the risk of waterlogging data into the "urban waterlogging model" for risk simulation. This method is a more scientific and realistic approach to the risk assessment of the daily flood risk distribution.

\section{Calculation Example}

2017 Changchun city government announced the city of 18 easy waterlogging points, and 24 easy waterlogging palace under the horizontal bridge and culvert. This article chooses "Renmin Street Fourth Ring Road Bridge" as the object of simulation analysis. The selected horizontal bridge and culvert length is $600 \mathrm{~m}$, of which the west side of the lead length is $378 \mathrm{~m}$, the eastern side of the approach is 180 meters, the slope was $3.5 \%$ and $5.3 \%$, the bridge width of $43 \mathrm{~m}$. Bridge and culvert drain 14 (east side of the five, the west side of the nine). The outlet diameter is $300 \mathrm{~mm}$. It is easy to 
calculate the self-catchment area of the bottom of the overpass at $1.62 \mathrm{hm}^{2}$. In order to analyze the influence of the ground elevation change on the catchment area, it is necessary to calculate the width of the bridge on both sides of the bridge. $15 \mathrm{~m}$ or $25 \mathrm{~m}$, the sink area becomes $2.52 \mathrm{hm}^{2}$ or $3.12 \mathrm{hm}^{2}$, and the three sets of data will be used when the risk simulation is carried out. The data collected into the "urban waterlogging model" were used to simulate the water depth, risk probability and duration of the waterlogging point by Monte Carlo simulation and self - help method.

The simulation shows that the recurrence period is a very important disaster factor. The following figure shows the distribution of the depth of the bottom of the bridge when the salinity area is $1.62 \mathrm{hm}^{2}$ and the greening rate is $18 \%$ on both sides of the road. It can be seen from the figure below that when the reproduction period is improved, the depth of the water is gradually increased, and the probability of forming the waterlogging disaster is gradually increased. For the 100 -year period of heavy rain, the depth of water depth is 0.6 meters, and the reproduction period of 5 years of rainfall, the depth of the water was 0.25 , the gap is great.

From the simulation calculation, we can see the relationship between the depth of water and the greening rate and the reproduction period. The following table shows the crossover table for the depth of the water depth. From the table is not difficult to find: fixed catchment area conditions, the depth of water with the greening rate is inversely proportional to the reproduction period is proportional to the corresponding green rate in the fixed conditions, the depth of water with the catchment area is proportional to, Is inversely proportional to the reproduction period. catchment area

Table 1 catchment area 1.62 conditions, the depth of water depth list (unit: meters)

\begin{tabular}{c|c|c|c}
\hline $\begin{array}{c}\text { Green Rate } \\
\text { Reproduction Rate }\end{array}$ & $0 \%$ & $18 \%$ & $30 \%$ \\
\hline 5 & 0.28 & 0.18 & 0.10 \\
10 & 0.35 & 0.25 & 0.20 \\
25 & 0.46 & 0.33 & 0.30 \\
50 & 0.54 & 0.40 & 0.38 \\
100 & 0.58 & 0.45 & 0.40 \\
\hline
\end{tabular}

\section{Conclusion}

The simulation results show that the recurrence period is a very important risk factor. For extreme weather, the meteorological department should promptly report the rainstorm warning and inform the public of the disaster level promptly. The traffic police department shall make temporary traffic control on the sections of the precarious water in advance to avoid the occurrence of disasters and tragedies. In addition, the drainage system design standards lag behind the pace of urban construction, for low-lying areas should be additional drainage equipment, traffic flow and crowded areas will be designed to improve the reproduction period to 50 years or 100 years. Similar to the subway mouth, underground car park, concave overpass the building should be carried out risk assessment of waterlogging, and according to the assessment results with large water pumps and other drainage facilities. The government should continue to promote rain and sewage diversion work, to avoid heavy rain when the water pipe network blockage. The simulation results also show that raising the level of greening on both sides of the road can reduce the risk of waterlogging when the reproduction period is small. In the process of urban construction, sacrificing part of the green belt to broaden the road is used in many areas of the method, but the simulation shows that this will increase the risk of waterlogging, so to maintain a moderate level of greening, the use of permeable brick and other water permeability better material for the prevention of waterlogging Very necessary.

The main innovation of this paper is to introduce the simulation method and the self-help method 
into the risk assessment of the urban waterlogging model. The risk probability value contains the historical rainfall distribution information of the locality, so the result of the evaluation is more practical. Urban waterlogging risk assessment has realistic needs, integrated information resources reflect the development of large data requirements. Waterlogging research in line with national "thirteen five" plan and the recent State Council requirements.

\section{Acknowledgements}

This article is supported by the Jilin Provincial Department of Education Project (2016102).

\section{References}

[1] Jinkang Du, Li Qian, Hanyi Rui, Tianhui Zuo, Dapeng Zheng, Youpeng Xu, C.-Y. Xu. Assessing the effects of urbanization on annual runoff and flood events using an integrated hydrological modeling system for Qinhuai River basin, China[J]. Journal of Hydrology . 2012

[2] S. Suriya,B.V. Mudgal. Impact of urbanization on flooding: The Thirusoolam sub watershed A case study[J]. Journal of Hydrology . 2011

[3] Surface water flooding risk to urban communities: Analysis of vulnerability, hazard and exposure[J]. Landscape and Urban Planning . 2011 (2)

[4] Hans de Moel,Jeroen C.J.H. Aerts, Eric Koomen. Development of flood exposure in the Netherlands during the 20th and 21st century[J]. Global Environmental Change . 2010 (2)

[5] Lisa Rygel, David O'sullivan, Brent Yarnal. A Method for Constructing a Social Vulnerability Index: An Application to Hurricane Storm Surges in a Developed Country[J]. Mitigation and Adaptation Strategies for Global Change . 2006 (3)

[6] Yong Shi, Chun Shi, Shi-Yuan Xu, A-Li Sun, Jun Wang. Exposure assessment of rainstorm waterlogging on old-style residences in Shanghai based on scenario simulation[J]. Natural Hazards . 2010 (2)

[7] Dapeng Huang, Chuang Liu, Huajun Fang, Shunfeng Peng. Assessment of waterlogging risk in Lixiahe region of Jiangsu Province based on AVHRR and MODIS image[J]. Chinese Geographical Science . 2008 (2)

[8] Qiu J. Urbanization contributed to Beijing storms. Nature News\&Comment . 2012

[9] Sang Y K,Wang Z G,Liu C M.What factors are responsible for the Beijing Storm. Natural Hazards . 2013

[10] Wu Z H,Huang N E, Long S R,et al. On the Trend,Detrending,and variability of nonlinear and non stationary time Series. Proceedings of the National Academy of Sciences of the United States of America . 2007 